\title{
ANCANGAN LITERASI KRITIS CERPEN RUMAH TUHAN KARYA DYAN ANGGRAENI SEBAGAI PENDIDIKAN KARAKTER, MORAL, DAN SOSIAL
}

\author{
Setiawan $^{1}$ dan Dindin M. Z. M. ${ }^{2}$ \\ Program Studi Pendidikan Bahasa dan Sastra Indonesia \\ Fakultas Keguruan dan Ilmu Pendidikan - Universitas Pasundan Bandung \\ Surel: setiawan@unpas.ac.id
}

\begin{abstract}
Abstrak
Sastra menjadi salah satu bagian dalam usaha dunia pendidikan untuk menumbuhkan karakter kepada siswa dengan memberikan segala bentuk karya sastra atau teks sastra salah satunya cerpen yang menjadi bagian dari prosa fiksi. Masalah dalam penelitian ini antara lain: (1) bagaimanakah ancangan literasi kritis pada cerpen Rumah Tuhan?; dan (2) bagaimanakah pendidikan karakter, moral, dan sosial pada cerpen Rumah Tuhan? Tujuan dalam penelitian ini yaitu: (1) mendeskripsikan ancangan literasi kritis dalam cerpen Rumah Tuhan; dan (2) mendeskripsikan pendidikan karakter, moral dan sosial dalam cerpen Rumah Tuhan. Metode yang digunakan dalam penelitian ini metode deskriptif analitik. Metode penelitian ini digunakan untuk menganalisis unsur intrinsik, ekstrinsik dan tinjauan literasi kritis yang terdapat dalam cerpen Rumah Tuhan karya Dyan Anggraeni. Berdasarkan analisis tersebut diketahui bahwa dalam cerpen Rumah Tuhan karya Dyan Anggraeni terdapat unsur intrinsik dan ekstrinsik yang mampu memberikan pesan pendidikan karakter, moral, dan sosial pada setiap bagian cerita yang disajikan.
\end{abstract}

Kata Kunci: literasi kritis, cerpen, pendidikan karakter, moral, sosial

\section{Abstract}

Literature is part of the efforts of the world of education to foster character in students by providing all forms of literary works or literary texts, one of which is short story as a part of fictional prose. The problems in this research are (1) How is the critical literacy approach in the short storynof RumahTuhan (2) How is the character, moral and social education in the short story of Rumah Tuhan? The objectives of this research are (1) to describe the critical literacy approach in the short story of Rumah Tuhan, (2) to describe the characters, moral and social education in the short story of Rumah Tuhan. The method used in this research is descriptive analytics method. This research method is used to analyze the intrinsic, extrinsic elements and critical literacy reviews contained in the short story of Rumah Tuhan by Dyan Anggraeni. Based on the analysis, there are intrinsic and extrinsic elements that are able to provide character, moral and social education messages in every part of the story presented.

Keywords: critical literacy, short stories, character education, moral, social 


\section{PENDAHULUAN}

Pembelajaran cerpen saat ini merupakan bagian dari pembelajaran teks sastra secara umum. Para pengajar Bahasa dan Sastra Indonesia di sekolah maupun perguruan tinggi secara dinamis terus mengembangkan pola analisis yang akan disajikan kepada peserta didik atau mahasiswa. Hal itu dilakukan untuk terus memberikan kualitas pembelajaran sastra yang optimal guna memberikan pesan-pesan sastra yang hendak akan diterima oleh siswa atau mahasiswa.

Banyak cara atau metode analisis yang sudah diberikan oleh para ahli bagaimanakah kaitan antara teks sastra dengan dampak pemahaman yang dirasakan oleh pembaca (siswa/mahasiswa) dengan berbagai hasil yang bervariatif. Analisis-analisis yang sudah dilakukan di lapangan cenderung membahas dan menganalisis hanya sebatas penempatan struktur atau unsur yang terdapat dalam cerpen saja dengan tidak mengaitkan pesan-pesan yang terkandung dalam teks tersebut.

Analisis atau kajian dari sebatas pengetahuan struktur atau unsur dalam cerpen hanya akan mengajak siswa ke arah kognitif parsial dalam memahami teks dan tidak membedah atau mengkaji cerpen secara utuh dan sempurna dengan mengkaji makna tersirat dalam teks dan kaitannya dengan konteks teks yang disajikan.

Berdasarkan uraian tersebut, peneliti bermaksud meneliti cerpen dengan ancangan literasi kritis sebagai pembentukan karakter, religius, moral, dan sosial.

Rumusan masalah dalam penelitian ini adalah (1) bagaimanakah ancangan literasi kritis pada cerpen Rumah Tuhan? Dan bagaimanakah pendidikan karakter, moral dan sosial pada cerpen Rumah Tuhan?

Tujuan dalam penelitian ini untuk mendeskripsikan ancangan literasi kritis dalam cerpen Rumah Tuhan dan mendeskripsikan pendidikan karakter, moral, dan sosial dalam cerpen Rumah Tuhan.

Konsep literasi kritis pada hakikatnya sangat erat kaitanya dengan berpikir kritis secara umum. Dilihat dari definisi berpikir kritis menurut Robert Ennis dalam Fisher (2009: 4) bahwa berpikir kritis adalah pemikiran yang masuk akal dan reflektif yang berfokus untuk memutuskan apa yang mesti dipercaya atau dilakukan. Pendapat lain yang menguatkan diungkapkan Johnson dan Freedman dalam Priyatni (2015: 28) mengungkapkan bahwa literasi kritis merupakan perpaduan antara ketarampilan berpikir kritis dan perhatian pada keadilan sosial, politik, bahasa, dan kekuasaan dalam teks.

Dalam tataran praktis menurut Priyatni (2015: 31) bahwa ancangan literasi kritis bisa dilakukan dengan mengajak pembaca memahami teks sastra dan menemukan pola-pola bahasa yang menyuarakan ide-ide khusus tentang kekuasaan, penindasan yang didasarkan pada ras. Salah satu teks yang bisa dikaji dengan menggunakan ancangan liferasikritis adalah cerpen.

a dan Cerpen adalah salah satu genre dalam prosa fiksi yang cukup banyak diminati oleh para pembaca fiksi di Indonesia dikarenakan panjang teks yang biasa disajikan tidak terlalu panjang seperti penamaannya. Menurut Sedgwick seperti yang dikutip Tarigan (2011: 179) bahwa cerpen adalah penyajian suatu keadaan tersendiri atau suatu kelompok keadaan yang memberikan kesan yang tunggal pada jiwa pembaca. Dikatakan tunggal karena 
titik permasalahan yang diberikan dalam sebuah cerpen tidak banyak penyimpangan atau digresi penceritaan, sehingga pembaca bisa secara langsung memahami maksud dari suatu cerpen. Pada saat ini masih banyak kesulitan yang ditemukan pembaca dalam memahami makna yang terkandung dalam cerpen. Hal utama yang tidak didapatkan pendidikan karakter yang terkandung dalam cerpen.

Pendidikan karakter tahun 2017 sedang menjadi perbincangan hangat setelah dikeluarkannya Perpres Penguatan Pendidikan Karakter (PPK) oleh Presiden Republik Indonesia Bapak Ir. Jokowi. Pendidikan karakter menurut Al-Attas dalam majalah Risalah (2017: 27) bisa dipahami sebagai adab yang dimaknai sebagai kemauan dan kemampuan seseorang untuk meletakkan sesuatu pada tempatnya, sesuai harkat dan martabat yang ditentukan Allah

Pada penelitian ini, peneliti bertujuan untuk mengetahui pendidikan karakter yang terkandung dalam cerpen Rumah Tuhan karya Dyan Anggraeni dengan menggunakan ancangan literasi kritis sebagai konsep penelaahan.

Uraian di atas, membuat peneliti tertarik untuk mengembangkan uraian permasalahan apresiasi sastra Jpada mahasiswa dengan objek sastra genre prosa fiksi yaitu cerpen. Hal yang difokuskan dalam penelitian ini adalah menggunakan konsep ancangan literasi kritis terhadap karakter religius dan sosial dalam karya sastra khususnya cerpen "Rumah Tuhan karya Dyan Anggraeni" untuk menambah khazanah sastra dalam hal bahan ajar prosa fiksi Indonesia yang digunakan mahasiswa di perguruan tinggi. Sekaitan dengan hal itu, maka peneliti membuat penelitian dengan judul "Ancangan Literasi Kritis
Cerpen Rumah Tuhan Karya Dyan Anggraeni sebagai Pembentukan Karakter Religius dan Sosial.

\section{METODE}

Dalam penelitian ini, digunakan jenis penelitian kualitatif. Menurut Sugiyono (2010: 15) yang dimaksud penelitian kualitatif adalah metode penelitian yang berlandaskan pada filsafat postpositivisme, digunakan untuk meneliti pada kondisi objek yang alamiah, (sebagai lawannya adalah eksperimen) di mana peneliti adalah sebagai instrumen kunci, pengambilan sampel sumber data dilakukan secara purposive, teknik pengumpulan dengan trianggulasi (gabungan), analisis data bersifat induktif/kualitatif, dan hasil penelitian kualitatif lebih menekankan makna dari pada generalisasi. Metode yang digunakan dalam penelitian ini adalah metode deskriptif analitik. Metode penelitian ini digunakan untuk menganalisis unsur intrinsik, ekstrinsik dan tinjauan literasi kritis yang terdapat dalam cerpen Rumah Tuhan karya Dyan Anggraeni. Sumber data yang sesuai dengan masalah penelitian yaitu teks cerpen Rumah Tuhan karya Dyan Anggraeni sebagai representatif dari karya sastra berbentuk prosa fiksi dari menre sastra Indonesia baru yang banyak dik dibàca khalayak banyak.

\section{HASIL DAN PEMBAHSAN}

\section{Analisis unsur Intrinsik dalam cerpen Rumah Tuhan}

a. Tema

Suatu prinsip hidup yang dipegang teguh oleh seseorang.

Hampir isi cerpen tersebut menggambarkan bahwa Ibu ialah orang yang meyakini bahwa bertandang ke rumah yang sedang sakit itu sama saja dengan datang ke rumah Tuhan 
walaupun, anaknya bertolak belakang dengan prinsip Ibu. Namun, ia tetap memegeang teguh prinsip tersebut.

\section{b. Alur}

Alur maju-mundur ini digambarkan oleh tokoh anak yang menceritakan permasalahan rumah tangga kedua orang tuanya dahulu. Hal ini dibuktikan dalam kutipan berikut.

"Tak seperti haru-biru Ibu yang bertahan dengan harga diri dan cintanya. Ayah justru senantiasa goyah dan berkali-kali ingin kembali. Tapi pertahanan Ibu memang telah solid melindungi dirinya dari kuasa cinta Ayah. Rumah tangga Ayah yang baru sama bobroknya dengan yang lama. Bedanya, kesalahan bukan dari sudutnya lagi seperti yang terjadi antara dirinya dan Ibu. Ayah sudah mengkhianati Ibu, begitu pula nasib yang didapatnya kemudian."

\section{1) Alur Pengenalan}

Pengenalan dari cerpen ini ialah terdapat di awal ketika anak sedang mendeskripsikan bagaimana ibunya tersebut. Hal ini diperkuat dengan bukti kutipan sebagai berikut.

"Ibuku adalah perempuan pemilik jiwa yang hangat. Rasa cinta padà sesama telah dibungkusnya dengan rapat, ikhlas, tanpa ada sebuah cela bernama pamrih yang bisa mendadak dan merobeknya. Dia perempuan yang pernah menikmati bahagia bagi dirinya sendiri dan telah merasa puas. Kini bahagianya sudah mencapai tingkat sempurna, merasa tanpa merasa."

\section{2) Alur Konflik}

Konflik pada cerpen ini adalah ketika anak membantah pada ibunya karena tidak ingin ikut bersama ibunya bertandang ke rumah seseorang yang sedang sakit. Hal ini dibuktikan pada kutipan sebagai berikut.

"Kau tak mau mengantar Ibu?"

"Aku sedang tak ingin pergi kemana-mana, Bu. Ke rumah Tuhan sekalipun.”

"Lancang! Tuhan mendengar perkataanmu dan malaikat mencatatnya. Sebagai ganjaran, kelak jika waktumu tiba, kau akan tertunda di muka gerbang surga menunggu kepastian-Nya. Kepanasan dan sendirian!"

\section{3) Alur Klimaks}

Klimaks pada cerpen ini adalah ketika anak mengetahui bahwa seseorang yang sakit ini ialah ayahnya. Rumah yang mereka kunjung pun adalah rumah ayahnya yang telah menyakiti dan mengkhianati mereka dengan lari kepada perempuan lain. Hal ini dibutikan pada kutipan sebagai berikut.

"Marilah, Bu," ajakku. Tak sudi aku berlama-lama di tempat itu. Lebih tak sudi lagi melihat cinta yang kadang-kadang mesih berkobar di matanya. Aku tahu, sudah beberapa kali Ayah datang untuk keminta maaf dan ingin kembali kepada ibu. Tapi ibu tak merasa harus memaafkan mempergunakan haknya. Selepas Ayah pergi, satu-satu pintu memang telah ditutupnya walaupun cinta tentu saja tak pernah mati."

4) Alur Anti-klimaks

Anti klimaks ini adalah ketika ibu menyuruh pada anaknya untuk berusaha 
untuk tersenyum di depan ayahnya yang sedang sakit, walaupun hanya berpurapura dan tahu bahwa anak memang sangat membenci kepada ayahnya. Hal ini dibuktikan pada kutipan sebagai berikut.

"Di depan pintu kamar Ayah, Ibu berhenti sejenak. Lengannya merangkul leherku dan diletakkan bibirnya pada telingaku, berbisik, "Pasang senyuman terbaikmu." Seketika pintu rumah Tuhan terbuka."

\section{c. Tokoh}

Tokoh dalam cerpen Rumah Tuhan ini hanya terdiri dari Ibu, Anak dan Ayah.

d. Watak

1) Ibu: Penyabar dan tidak pendendam walaupun telah dikhianati oleh mantan suaminya yaitu Ayah masih tetap bersedia datang di kala Ayah sakit.

"Ibuku adalah perempuan pemilik jiwa yang hangat. Rasa cinta pada sesama telah dibugkusnya dengan rapat, ikhlas, tanpa ada sebuah cela bernama pamrih yang bisa didesak dan merobeknya...."

\section{Jurnal Ilmiah}

2) Anak: Kritis dan pendendam.Hal ini terlihat ketika ia terus menanyakan tentang makna rumah Tuhan bagi ibunya karena ia tidak mengerti mengapa ruma Tuhan sebanyak itu. Lalu, sedikit pendendam karena ia mengtuk ayahnya yang sedang sakit dengan berharap Tuhan tak ada bersama ayah dikala sakit.

"Kenapa rumah Tuhan tak satu saja? Akan lebih mudah, " kataku suatu hari saat dia memintaku mengantarnya untuk kesekian kali...."

3) Ayah: pengkhianat. Dalam cerpen ini watak Ayah tidak terlalu banyak dijelaskan, dikarenakan bukan tokoh utama pada cerpen ini. Namun, hanya sekilas digambarkan yaitu seorang pengkhianat yang mengkhianati ibu dan anaknya dengan tergoda oleh wanita lain hingga perkawinannya hancur.

"Rumah tangga Ayah yang baru sama bobroknya dengan yang lama."

4) Latar/Setting

(a) Siang hari

"Tak peduli di siang hari yang panas maupun malam dengan kegelapan yang nyata."

(b) Halaman rumah kami "Seakan-akan doa telah dirapalkan dalam hati sejak kakinya menjejak heksagon paving block terakhir halaman rumah kami."

(c) Jalanan kecil "Bergegas kunyalakan mesin sepeda motor, berharap masih tercium aroms tubuhnya di jalanan kecil yang dilewati agar bisa kudapatkan dia."

(d) Rumah Ayah

"Tuhan menyambangi

(e) Di depan pintu kamar Ayah "Di depan pintu kamar Ayah, Ibu berhenti sejenak." 
5) Sudut Pandang

Sudut pandang orang pertama. Menggunakan kata ganti 'Aku'.

"Tanpa bermaksud memungkiri bahwa aku adalah anak kurang ajar ketika harus menahan hati dari memakidiri sendri..."

6) Gaya Bahasa

Gaya bahasa yang digunakan dalam cerpen ini adalah gaya bahasa sehari-hari yang mudah dimengerti

"Ibuku adalah perempuan pemiliki jiwa yang hangat. Cinta pada sesama telah dibungkusnya dengan rapat, ikhlas tanpa ada sebuah cela ..."

7) Amanat

Amanat yang bisa diambil dari cerpen ialah sebuah prinsip makna hidup yang kokoh dan dipegang teguh hingga kapanpun dengan dan oleh siapapun. Lalu, sebuah sebuah kunci yaitu kesabaran dan keikhlasanlah untuk memegang teguh sebuah prinsip itu walau sebesar dan sekuat apapun cobaan menghadang pasti bisa dilaluinya dengan memegang kunci tersebut. $\|$ mSIMPULAN

Pendidikan Błerdasárkan penelitian yang

2. Analisis unsur Eksterinsik cerpen Rumah Tuhan

Nilai yang terkandung dalam cerpen tersebut adalah nilai.

a. Nilai religius terletak pada Ibu yang memercayai bahwa Tuhan selalu bertandang pada seseorang yang sedang sakit. Maka dari itu, Ibu selalu datang ke rumah yang penghuninya sedang sakit karena ia menganggapnya itu juga rumah Tuhan.
“... Setiap jengkal jarak yang kita tempuhakan dikumpulkan malaikat untuk ditaburkan di ranjang sisakit.... Sakit seseorang juga merupakan sebuah peringatanTuhan agar kita makin merasa dekat dengan-Nya..."

b. Nilai moral, ketika suatu hari ibu dan anaknya datang ke rumah seseorang yang sedang sakit dan ternyata mantan suami sekaligus dari ibu dan ayah bagi si Anak. Namun, hebatnya Ibu tidak merasa dendam atau tidak ingin berkunjung untuk melihat ia dengan ikhlas datang walupun mempunyai kenangan yang buruk oleh lelaki tersebut.

“... disiapkannya sendiri barangbarang bawaan yang hendak dipersembahkan pada si sakit ..."

\section{c. Nilai Sosial}

Kondisi sosial yang diceritakan dalam cerpen ini merupakan kondisi sosial yang ada di masyarakat, kehidupan keluarga kecil tanpa Ayah karena perceraian.

"Rumah tangga Ayah yang baru sama bobroknya dengan yang lama."

dilakukan seperti halnya di atas, maka peneliti menyimpulkan bahwa cerpen Rumah Tuhan karya Dyan Anggraeni mengandung unsur intrinsik dan ekstrinsik yang memberikan pemaknaan pendidikan karakter dengan penguatan pada nilai-nilai seperti nilai moral, religius dan sosial yang mampu memberikan pengaruh positif bagi pembaca secara umum dan memberikan pemaknaan sastra dalam hal ini cerpen sebagai salah satu aspek yang 
memberikan pendidikan karakter dengan penguatan nilai-nilai yang melekat pada cerpen.

\section{DAFTAR PUSTAKA}

Fisher, Alec. 2008. Berpikir Kritis sebuah Pengantar. Jakarta: Erlangga.

Jejen. 2017. Pendidikan Karakter. Bandung: Majalah Risalah.

Prityatni, E, T. 2015. Membaca Sastra dengan Ancangan Literasi Kritis. Jakarta: Bumi Aksara.

Sugiono. 2010. Metode Penelitian Pendidikan Pendekatan Kuantitaif, Kualitatif dan R\&D. Bandung: Alfabeta.

Tarigan, Henry Guntur. 2011. PrinsipPrinsip Dasar Sastra. Bandung:

Angkasa. 